\title{
PATIENTS WITH SUICIDE ATTEMPT; DEMOGRAPHIC PROFILE OF REPORTING TO TWO TERTIARY CARE HOSPITALS AT HYDERABAD, PAKISTAN
}

1. MBBS, DPM,(MD Psychiatry) Specialist Psychiatrist

Sir Cowsjee Jehangir Institute of Psychiatry

(CJIP) Hyderabad

2. Associate Professor

Department Of Psychiatry,

Shaheed Mohtarma Benazir Bhutto Medical University,

Chandka Medical College Larkana

3. MBBS, DPM, FCPS

Assistant Professor

Ghulam Muhammad Mahar Medical College (GMC) Hospital Sukkur

4. PhD Psychiatry

Senior Lecturer

University Pendidkan Sultan Idress

Tanjong Malim, Pearl Malaysia

Correspondence Address:

Dr Jamil Junejo

House No. C/6 old Wahdat Colony,

Hyderabad.

jameljunejo@gmail.com

Article received on:

06/04/2015

Accepted for publication:

17/06/2015

Received after proof reading:

12/10/2015

\section{Dr. Jamil Junejo', Dr. Badaruddin Junejo², Dr. Inayatullah Awan ${ }^{3}$, Dr. Asma Perveen ${ }^{4}$}

ABSTRACT... Objective: To determine the demographic details (gender, age, marital status, level of education, and occupation) of suicide attempters attending the tertiary care hospital services at Hyderabad, Pakistan. Study Design: Cross sectional study. Setting: Liaquat university hospital Hyderabad and Sir Cowasjee Jahangir Institute of psychiatry (CIJP) Hyderabad. Period: Twelve months from the 1st January 2011 to 31st December 2011. Methodology: The aim of the study was. Patients with a history of attempted suicide. Two hundred (200) consecutive cases were recruited and selected according to the inclusion criteria. An informed consent was obtained from patients for being included in the study. A specially designed semistructured Proforma was used to record demographic details of the patients. Data were entered into and analyzed through statistical software SPSS version 20. Results: Total 200 hundred cases were included in the study. Males $78.5 \%(\mathrm{~N}=157)$ outnumbered female patients 21.5 $\%(\mathrm{~N}=43)$. The age range of study subjects was between $15-59$ years. Mean age of the total cases was 22.6 years. Majority of the patients presenting with suicide were single comprising $61 \%(N=122)$ of study cases with a $P$ value $<0.001$. Total cases of married subjects were 27.5 $\%(\mathrm{~N}=55)$ with a $\mathrm{P}$ value $<0.001$. While $5.5 \%$ subjects were separated and $6 \%$ were divorced. Unskilled labors made the largest group comprising of $24.5 \%(\mathrm{~N}=49)$ of all the cases. Other occupations included farmers (15.5\%), skilled labor (15\%), jobless $(11.5 \%)$, house wives $(8.5$ $\%)$, students $(7 \%)$, and shopkeepers $(6 \%)$. Out of the total 200 patients with attempted suicide $32 \%$ were illiterate, $33.5 \%$ were educated up to primary level, $19.5 \%$ were matriculate, $09 \%$ were intermediate passed, and only $6 \%$ were graduate. (Table-II). Conclusion: In Pakistan still Suicide attacks are reported. Our results suggest that suicidal thoughts can be entirely predict by common reported in male and younger age due to very sensitive to family issues, lower education level and major depression due to unemployment or low level earning of unskilled labor occupation in the Pakistan population.

Key words: $\quad$ Suicide Attempters, demographic factors, Psychiatric Disorder.

Article Citation: Junejo J, Junejo B, Awan I, Perveen A. Patients with suicide attempt; demographic profile of reporting to two tertiary care hospitals at Hyderabad, Pakistan. Professional Med J 2015;22(10):1321-1326. DOI:10.17957/ TPMJ/15.2879

\section{INTRODUCTION}

Suicide attempt is a situation in which a person has performed an actual or seemingly life-threatening behavior with the intent of jeopardizing his/her life, or to give the appearance of such an intent but not resulting into death. ${ }^{1}$ Skogman, $\mathrm{K}$ (2001) studied gender differences and reported that men have a higher frequency of suicide and greater overall mortality from suicide than women. ${ }^{2}$ The association between suicidal behavior and gender is, however, paradoxical; although female show high rates of attempted suicide while males frequently complete more suicide. ${ }^{3}$ Studies have identified that younger (15-24 years) and el- derly (65 years) make two high suicide groups. ${ }^{4}$ With regard to marital status, it has been consistently found that married person have lower suicide rates than people who are single, widowed, or divorced. ${ }^{5,6}$

In the prospective Christchurch Health Development study, unemployment was found to be significantly related to increased risk of suicidal behavior. After adjustment for confounding and reverse causality, this association was substantially reduced but remained significant. ${ }^{7,8,9}$ A series of studies identified particular occupational groups with increased risk of suicide. These groups in- 
clude police, miners, farmers, and veterinarians ${ }^{10}$. In general, risk of suicide and suicide attempt are elevated among individuals who have poor or limited education. ${ }^{11}$ It is likely that the major route by which poor education leads to suicidal behavior is as a result of links between socioeconomic factors and mental health. ${ }^{12,13}$

According to World Health Organization rating system Pakistan is at level 04 and rated poor to report mortality from suicide. ${ }^{14}$ There have been few studies of attempted suicide from Pakistan, where the act is considered to be a criminal offence and the Islamic religion strongly prohibits and condemns any act of suicide. In order to address the problem, a retrospective case report analysis of all index cases of attempted suicide presenting over a period of 3.5 years to a university hospital in Karachi, Pakistan, was undertaken. Results showed that most of the subjects were young adults, married women representing the single largest group. Reports based on official police records do not reflect the true picture of the problem in Pakistan. ${ }^{15,16}$ There is accumulating anecdotal evidence that suicide rates have been gradually increasing in Pakistan over the last few years. ${ }^{1}$

\section{MATERIAL AND METHODS}

This was a cross sectional study of patients with a history of attempted suicide who were brought to Liaquat university hospital Hyderabad and Sir Cowasjee Jahangir Institute of psychiatry (CIJP) Hyderabad over a span of twelve months from the 1st January 2011 to 31st December 2011. The aim of the study was to determine the demographic details (gender, age, marital status, level of education, and occupation) of suicide attempters attending the tertiary care hospital services.

Two hundred (200) consecutive cases were recruited and selected according to the inclusion criteria. An informed consent was obtained from patients for being included in the study. A specially designed semi-structured Proforma was used to record demographic details of the patients. Data were entered into and analyzed through statistical software SPSS version 20.

\section{RESULT}

Total 200 hundred cases were included in the study. Males $78.5 \%(\mathrm{~N}=157)$ outnumbered female patients $21.5 \%(\mathrm{~N}=43)(\mathrm{Fig}-1)$.

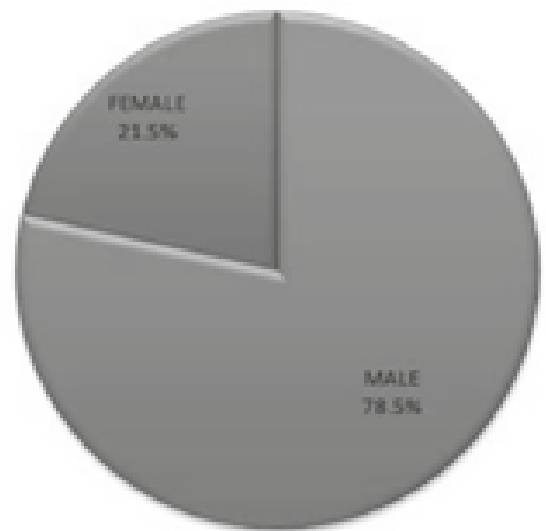

Fig-1. Gender distribution

The age range of study subjects was between $15-59$ years. Mean age of the total cases was 22.6 years. Age of the study subjects was distinguished into eight sub-groups with five years' difference. The largest number of subject fell in the age group i.e. $35.5 \%(\mathrm{~N}=71)$ with a $p$ value of 0.415 (Table-I)

Majority of the patients presenting with suicide were single comprising $61 \%(\mathrm{~N}=122)$ of study cases with a $P$ value $<0.001$. Total cases of married subjects were $27.5 \%(\mathrm{~N}=55)$ with a $\mathrm{P}$ value $<0.001$. While $5.5 \%$ subjects were separated and $6 \%$ were divorced. (Table-II).

The Occupation of suicide attempters. Unskilled labors made the largest group comprising of 24.5 $\%(\mathrm{~N}=49)$ of all the cases. Other occupations included farmers (15.5\%), skilled labor (15\%), jobless $(11.5 \%)$, house wives $(8.5 \%)$, students $(7 \%)$, and shopkeepers (6\%). (Table-II)

Out of the total 200 patients with attempted suicide $32 \%$ were illiterate, $33.5 \%$ were educated up to primary level, $19.5 \%$ were matriculate, 09 $\%$ were intermediate passed, and only $6 \%$ were graduate. (Table-II). 


\begin{tabular}{|c|c|c|c|c|c|}
\hline S. No & Variable & Males (\%) & Females (\%) & Total cases (\%) & $P$ value \\
\hline 1. & $15-19$ & $12(7.6)$ & $12(27.9)$ & $24(12)$ & 0.003 \\
\hline 2. & $20-24$ & $58 \quad(36.9)$ & $13(30.2)$ & 71 (35.5) & 0.415 \\
\hline 3. & $25-29$ & $36 \quad(22.9)$ & $7 \quad(16.2)$ & $43 \quad(21.5)$ & 0.346 \\
\hline 4. & $30-34$ & $25 \quad(15.9)$ & $2 \quad(4.6)$ & $27 \quad(13.5)$ & 0.055 \\
\hline 5. & $35-39$ & $19 \quad(12.1)$ & $7 \quad(16.2)$ & $26 \quad(13)$ & 0.470 \\
\hline 6. & $40-44$ & $4 \quad(2.5)$ & $2 \quad(4.6)$ & $6 \quad(3)$ & 0.473 \\
\hline 7. & $45-49$ & $2 \quad(1.2)$ & 0 & $2 \quad(1)$ & 0.450 \\
\hline 8. & $50-59$ & $1 \quad(0.6)$ & 0 & $(0.5)$ & 0.599 \\
\hline \multicolumn{6}{|c|}{ Table-I. Gender-wise age differentiation } \\
\hline
\end{tabular}

\begin{tabular}{|c|c|c|c|c|c|}
\hline \multicolumn{6}{|c|}{ Marital status of the suicide attempters } \\
\hline S. No & Variable & Males \% & Females \% & Total cases \% & $P$ value \\
\hline 1. & Singles & $109(69.4 \%)$ & $13(30.2 \%)$ & $122(61 \%)$ & $<0.001$ \\
\hline 2. & Married & $32(20.3 \%)$ & $23(53.4 \%)$ & $55(27.5 \%)$ & $<0.001$ \\
\hline 3. & Separated & $9(5.7 \%)$ & $2(4.6 \%)$ & $11(5.5 \%)$ & 0.782 \\
\hline 4. & Divorced & $7(4.4 \%)$ & $5(11.6 \%)$ & $12(6 \%)$ & 0.079 \\
\hline \multicolumn{6}{|c|}{ Occupation of the study subjects } \\
\hline S. NO & Variable & Males \% & Females \% & Total cases $\%$ & $P$ value \\
\hline 1. & House wife & 0.0 & $17(39.5 \%)$ & $17(8.5 \%)$ & $<0.001$ \\
\hline 2. & Student & $12(7.6 \%)$ & $2(4.6 \%)$ & $14(7 \%)$ & 0.495 \\
\hline 3. & Unskilled labor & $45(28.6 \%)$ & $4(9.3 \%)$ & $49(24.5 \%)$ & 0.008 \\
\hline 4. & Skilled labor & $27(17.1 \%)$ & $3(6.9 \%)$ & $30(15 \%)$ & 0.096 \\
\hline 5. & Farmer & $22(14 \%)$ & $9(20.9 \%)$ & $31(15.5 \%)$ & 0.266 \\
\hline 6. & Shopkeeper & $12(7.6 \%)$ & 0.0 & $12(6 \%)$ & 0.061 \\
\hline 7. & Jobless & $23(14.6 \%)$ & 0.0 & $23(11.5 \%)$ & 0.007 \\
\hline 8. & Others & $16(10.1 \%)$ & $8(18.6 \%)$ & $24(12 \%)$ & 0.132 \\
\hline \multicolumn{6}{|c|}{ Educational status } \\
\hline S. No & Variable & Male \% & Female \% & Total cases $\%$ & $P$ value \\
\hline 1. & Illiterate & $43(27.3 \%)$ & $21(48.8 \%)$ & $64(32 \%)$ & 0.007 \\
\hline 2. & Primary & $54(34.3 \%)$ & $13(30.2 \%)$ & $67(33.5 \%)$ & 0.608 \\
\hline 3. & Matriculation & $33(27.1 \%)$ & $6(13.9 \%)$ & $39(19.5 \%)$ & 0.300 \\
\hline 4. & Intermediate & $16(10.1 \%)$ & $2(4.5 \%)$ & $18(9 \%)$ & 0.260 \\
\hline 5. & Graduate & $11(7 \%)$ & $1(2.3 \%)$ & $12(6 \%)$ & 0.252 \\
\hline
\end{tabular}

\section{DISCUSSION}

In present study male patients outnumbered their female counterparts $(78.5 \% \mathrm{v} / \mathrm{s} 21.5 \%)$. This finding correlates with two studies which were previously conducted in Pakistan respectively by Khan MM et al (2006) ${ }^{18}$ and Hussain S.J et al (2009). ${ }^{19}$ In both of these studies male subjects dominantly attempted suicide. The finding is also consistent with the study of Ping Qin et al $(2000)^{20}$ which was conducted on gender difference in risk for suicide in Denmark where high risk was found in male gender. In a study carried out by Bannerjee et al (1990) ${ }^{21}$ it was found that men were three times more likely to attempt suicide than women. In contrast to the findings of present study Arun $\mathrm{M}$ et al (2004) 22 reported higher ratio of attempted suicide among females. Rosalie Shemanski $(2009)^{23}$ also reported that suicide attempts are 
three folds more common among females than males. This study found that $69 \%$ of the subjects fell in the age group of 15-29 years. This finding is consistent with the finding of a study conducted by Phillips MR (2002)who found that suicide is the fifth most important cause of death among young adults $15-34$ years of age. ${ }^{24}$

According to World Health Organization in Australia, Pakistan, Sri Lanka, and Thailand young people have the highest rates for suicide while in China, Hong Kong Japan, Malaysia, the Republic of Korea and Singapore suicide is a relatively greater problem for older people. Asian cultures like that of Pakistan, China, and Japan tend to be highly collectivistic whereas USA, Australia, and Britain have got highly individualistic culture. ${ }^{25,26}$

In our study singles (including divorced and separated) outnumbered the married $(72.5 \% \mathrm{v} / \mathrm{s}$ $27.5 \%)$. Rozita Ibrahim \& Zahara (2009) also concluded that suicide is more common among those who are single, recently separated, divorced, or widowed. The suicide rates are highest for widowed men and second highest for divorced men. Divorced women have a suicide rate almost four times that of married women, but widowhood does not impact on suicidal behavior in women to the extent that it does in men. ${ }^{6}$ In contrast to result of this study, findings of a study conducted at Karachi by Khan MM et al suggest that married women were more likely to attempt suicide than men and the causative factors included family conflicts, problems with their mothers-in-law and domestic violence. ${ }^{27}$

Kposowa, Augustine $\mathrm{J}$ et al (2000) concluded in their research that countries like India, Pakistan, and Sri lanka where arrange marriages are common, the social and familial pressure on woman to stay married even in abusive relationship appears to be one of the factors that increased the risk of attempted suicide in married woman ${ }^{6}$. Results of our study show that $24.5 \%$ cases were unskilled laborers. This finding is consistent with the research conducted by Conner KR et al (2004) which concluded that unemployment, retirement, and sickness/absence from work were the signif- icant risk factors for suicide ${ }^{28}$.

Khan MM et al (1998) ${ }^{27}$ and Morrell Stephen $L$ et al (1998) ${ }^{7}$ also found out through their researches that unemployment was important factor in attempted suicide among both genders whereas Johonsson LM et al (1997) ${ }^{29}$ found an evidence that occupational factors are particularly important in male suicide. Lewis $G$ et al $(1998)^{30}$ also found, that unemployment was significantly related to increased risk of suicidal behavior. In our study $32 \%$ subjects were illiterate, $33.5 \%$ were educated up to primary level, and only $6 \%$ were graduate. These findings correlate with the results of researches by Wasserman D et al (2006) ${ }^{31}$, Jacobs DG et al (2003) ${ }^{32}$ and Beautrais AL et al $(3003)^{23}$ who identified increased risk of suicide and suicide attempt among individuals who have poor or limited education. Rozita Ibrahim \& Zahara (2009) found in their study that the limited education is major route which leads to suicidal behavior ${ }^{6}$.Kaplan and Sadock also reported Low educational levels also responsible for suicide ${ }^{33}$.

\section{CONCLUSIONS}

In Pakistan still Suicide attacks are reported. Our results suggest that suicidal thoughts can be entirely predict by common reported in male and younger age due to very sensitive to family issues, lower education level and major depression due to unemployment or low level earning of unskilled labor occupation in the Pakistan population. Copyright@ 17 June, 2015.

\section{REFERENCES}

1. Beck A, Davis JR, Frederick CJ. Classification and nomenclature. Suicide preventionin the seventies 1972.

2. Skogman K, Alsen M, Ojehagen A. Sex difference for risik factors for suicide after attempted suicide. Social psychiatry and psychiatric epidemiology. 2004;39(2):113-120.

3. Dr Susan Blumenthal the nation's first deputy sectary for woman health. http://www.afsp.org/index-1.htm.

4. Rubenowitz E, Waern M., Wilhelmson K, Allebeck $P$. Life events and psycho-social factors in elderly suicides--a case-control study. Psychol Med.2001;31(7):1193-1202.

5. Carolyn TL. Risk factors for late-life suicide: a pro- 
spective, community-based study. American Journal of Geriatric Psych 10.4 (2002): 398-406.

6. Rozita I, Hassan Z. Understanding single -hood from the experiences of never-married Malay Muslim women in Malaysia: some preliminary findings. European Journal of Social Sciences, 2009;8(3):395-405.

7. Stephen ML, Taylor RJ, Kerr CB. Jobless. Unemployment and young people's health. Med J Australia 168.5 (1998): 236.

8. David ML, Horwood J, Woodward LJ. Unemployment and psychosocial adjustment in young adults: causation or selection. Social science \& medicine. 2001;51(1):305-320.

9. Fergusson DM, Lynsky MT. Childhood circumstances adolescent adjustment and suicide attempts in New Zealand birth cohort. Journal of the American academy of child and adolescent psychiatry.1995;34:612-22.

10. Kposowa AJ. Mortality in United States, Differentials by industrial and occupation groups. American journal of industrial medicine. 1999;36(6):645-52.

11. Beautrais AL. Suicides and serious suicide attempts: two populations or one American Journal of Psychiatry 2001;156:1563-1569.

12. Gunnell D, MagnussonPKE, Rasmussen F. Low Intelligence test scores in 18 years old men and risk of suicide: Cohort study British Medical Journal.2005;330:167-71.

13. Apply L, Cooper J, Amos T. Psychological autopsy study of suicide by people aged under age 35 years. British journal of psychiatry.1999;75:168-74.

14. Ghaffar A, Hyder AA, Bishai D. Newspaper reports as a source for injury data in developing countries. Health Policy Planning 2001;16:322-325.

15. Khan MM, Haider N, Prince M. Epidemiology of suicide in Pakistan: determining rates in six cities. Archives of suicide research 2008;12(2):155-160.

16. Khan MM, Islam S, Kundi AK. Parasuicide in Pakistan: experience at a university hospital Acta Psychiatry Scand, 1996;93(4):264-7.

17. Khan MM, Prince M. Beyond rates: the tragedy of suicide in Pakistan. Trop Doct 2003;33: 67-9.

18. Khan MM , Hyder AA. Suicide in developing world case study from Pakistan. Suicide and Life Threatening Behavior. 2006;36:76-81.

19. Hussain SJ, Ansari MA, Rahman R. A preliminary study of suicide attempters presented at Liaquat University Hospital Hyderabad. J Pak Psych Soc Jan - Jun 2009;6(1):17-20.

20. Qin P, Bo Mortensen P, Agerbo E. Gender difference in risk factor for suicide in Denmark. British Journal of Psychiatry 2000; 177:546-550.

21. Bannerjee G, Nandi D, Nandi S. The vulnerability of Indian women to suicide. Indian Journal of Psychiatry.1990;32:305-308.

22. Arun M, Yoganarasimha K, Palimar Vikram, Kar Nilamadhab, Mohanty Manoj Kumar. Para suicide: An approach to the profile of victims. Journal of Indian Academy of Forensic Medicine. 2004 Apr;26(2): 58-61.

23. Shemanski R, Cerel J. The Development of Effective Message Content for Suicide Intervention, Crisis. J Crisis Interv Suicide Prevention. 2009;30(4):174-179.

24. Phillips MR, Li X, Zhang Y. Suicide rates in China. Lancet, 359: 835-840, 2002.

25. World Health Organization. Figures and facts about suicide. Geneva, WHO, 1999.

26. W.H.O, The world health report 2000. Mental health: New Hope. Geneva: W , 2001 (http://www. who.int/ whr/2001/en/).

27. Rao AV. Parasuicide and suicide some psychological considerations. Indian Journal of Social Psychiatry. 1992;8:3-7.

28. Murphy GE. Psychiatric aspects of Suicidal behavior: Substance abuse. In K Hawton, Kvan Heeringen eds. The international hand book of suicide and suicide prevention.2000;135-146.

29. ConnerKR, ChiapellaP. Alcohol and suicidal behavior. Overview of research workshop. Alcoholism Clinical and Experimental Research 2004;28(5):25-27.

30. Johansson LM. Ethnicity, social factors, illness and suicide: a follow-up study of a random sample of the Swedish population. Acta Psychiatrica Scandin 1997;95(2):125-131.

31. Beautrais AL, Joyce PR, Mulder RT. Prevalence and co-morbidity of mental disorders in persons making serious suicide attempts: a case-control study. American Journal of Psychiatry.1999;153:1009-1014.

32. Hussain SJ,Nighat $A$, Zain $F$. Issue of the issueless male patient. Medical Channel 2007;17(4):97-99.

33. Pinikahana J, Happell B, Keks N. Suicide and schizophrenia: a review of the literature for the decade 


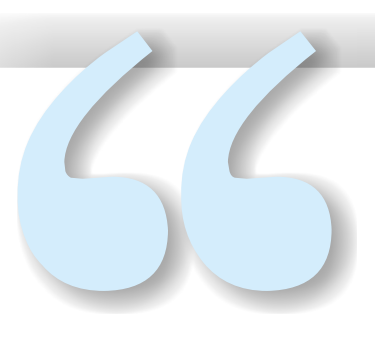

\section{"He who kneels before GOD can stand before anyone."}

\section{AUTHORSHIP AND CONTRIBUTION DECLARATION}

\begin{tabular}{|c|c|c|c|}
\hline Sr. \# & Author-s Full Name & Contribution to the paper & Author $=s$ Signature \\
\hline 1 & & & \\
\hline 3 & Dr. Inayatullah Awan & $\begin{array}{l}\text { Statistical expertise, Critical } \\
\text { revision of the article for } \\
\text { important intellectual } \\
\text { content } \\
\text { Drafting of the article }\end{array}$ & 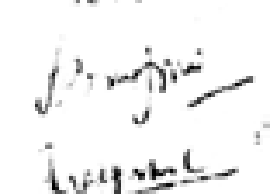 \\
\hline 4 & Dr. Asma Perveen & $\begin{array}{l}\text { Critical revision of the article } \\
\text { for important intellectual } \\
\text { content }\end{array}$ & $\iint d x:$. \\
\hline
\end{tabular}

